\title{
Continuity, segmentation and faulting type of active fault zones of the 2016 Kumamoto earthquake inferred from analyses of a gravity gradient tensor
}

\author{
Nayuta Matsumoto $^{1 *}\left(\mathbb{0}\right.$, , Hiramatsu Yoshihiro ${ }^{2}$ and Akihiro Sawada ${ }^{2}$
}

\begin{abstract}
We analyze Bouguer anomalies in/around the focal region of the 2016 Kumamoto earthquake to examine features, such as continuity, segmentation and faulting type, of the active fault zones related to the earthquake. Several derivatives and structural parameters calculated from a gravity gradient tensor are applied to highlight the features. First horizontal and vertical derivatives, as well as a normalized total horizontal derivative, characterize well the continuous subsurface fault structure along the Futagawa fault zone. On the other hand, the Hinagu fault zone is not clearly detected by these derivatives, especially in the case of the Takano-Shirahata segment, suggesting a difference of cumulative vertical displacement between the two fault zones. The normalized total horizontal derivative and the dimensionality index indicate a discontinuity of the subsurface structure of the Hinagu fault zone, that is, a segment boundary between the Takano-Shirahata and the Hinagu segments. The aftershock distribution does not extend beyond this segment boundary. In other words, this segment boundary controls the southern end of the rupture area of the foreshock. We also recognize normal fault structures dipping to the northwest in some areas of the fault zones from estimations of dip angles.
\end{abstract}

Keywords: First horizontal derivative, First vertical derivative, Normalized total horizontal derivative, Dip angle, Dimensionality index, Segment boundary, Aftershock distribution

\section{Introduction}

The 2016 Kumamoto earthquake consisted of the foreshock $\left(M_{\mathrm{JMA}} 6.5,21: 26 \mathrm{JST}\right.$ on April 14, 2016) and the mainshock $\left(M_{\mathrm{JMA}} 7.3,01: 25\right.$ JST on April 16, 2016). The focal mechanism of the foreshock was a right lateral slip, and the mainshock was a right lateral slip with a normal fault component (JMA 2016a, b). The sources of the foreshock and mainshock were located in the Takano-Shirahata segment of the Hinagu active fault zone and the Futagawa segment of the Futagawa active fault zone, respectively (GSI 2016a). The Headquarters for Earthquake Research Promotion of Japan (HERP 2013a) extended the Futagawa active

\footnotetext{
*Correspondence: n.matsumoto@stu.kanazwa-u.ac.jp ${ }^{1}$ Graduate School of Natural Science and Technology, Kanazawa University, Kakuma, Kanazawa 920-1192, Japan Full list of author information is available at the end of the article
}

fault zone to the west because steep horizontal gradients of Bouguer anomalies are distributed continuously to the end of the Uto Peninsula and a normal fault, the displacement of which reaches the sea floor, was revealed off the coast of Ota (AIST et al. 2010; Sugiyama et al. 2010). They divided the fault zone into the Futagawa segment, the Uto segment and the north coast of the Uto Peninsula segment.

The north-south extensional tectonics is dominant in central Kyushu (Tada 1984; Takayama and Yoshida 2007). The Beppu-Shimabara rift zone (Matsumoto 1979), of which the south end is bounded by the Oita-Kumamoto tectonic line, is a subsidence zone due to the extension and may lead to the Okinawa trough (Tada 1984, 1985) (Fig. 1). Major active fault zones in the study area, composed of normal faults extending in the EW direction, are the Minou and the Beppu-Haneyama fault zones, and right lateral faults with normal fault components 
extending in the NE-SW direction are the Futagawa, the Hinagu and the Midorikawa fault zones (HERP 2013b).

As shown in Fig. 2, in the middle part of Kyushu, Quaternary volcanic rocks and pyroclastic rocks are extensively deposited around the Beppu-Shimabara rift zone. From the south of the Oita-Kumamoto tectonic line to the Usuki-Yatsushiro tectonic line, the basement rocks are mainly Mesozoic metamorphic rocks and Cretaceous sedimentary rocks which are mostly covered with Quaternary pyroclastic rocks. To the south of the UsukiYatsushiro tectonic line, Paleozoic and Mesozoic accretionary complexes mainly accumulated.

Gravity anomaly analysis is useful for examining the subsurface structures of active fault zones. Fedi et al.
(2005) show the fine image of the structural setting in the southern Apennines which is obtained from analyzing several single components of a gravity gradient tensor. Also, there exist several studies of gravity anomalies around source faults of large earthquakes. From a comparison of gravity anomalies and aftershock distributions, Honda et al. (2002) have shown that the source area of the 2000 Tottori-ken Seibu earthquake was controlled by a geological boundary. Gravity analysis around the aftershock region of the 2007 Noto Hanto earthquake showed that the rupture size of the earthquake was constrained by block structures in the Noto Peninsula (Honda et al. 2008). In Kyushu, Nishijima and Fujimitsu (2015) reveal the fault structure of the Minou fault zone

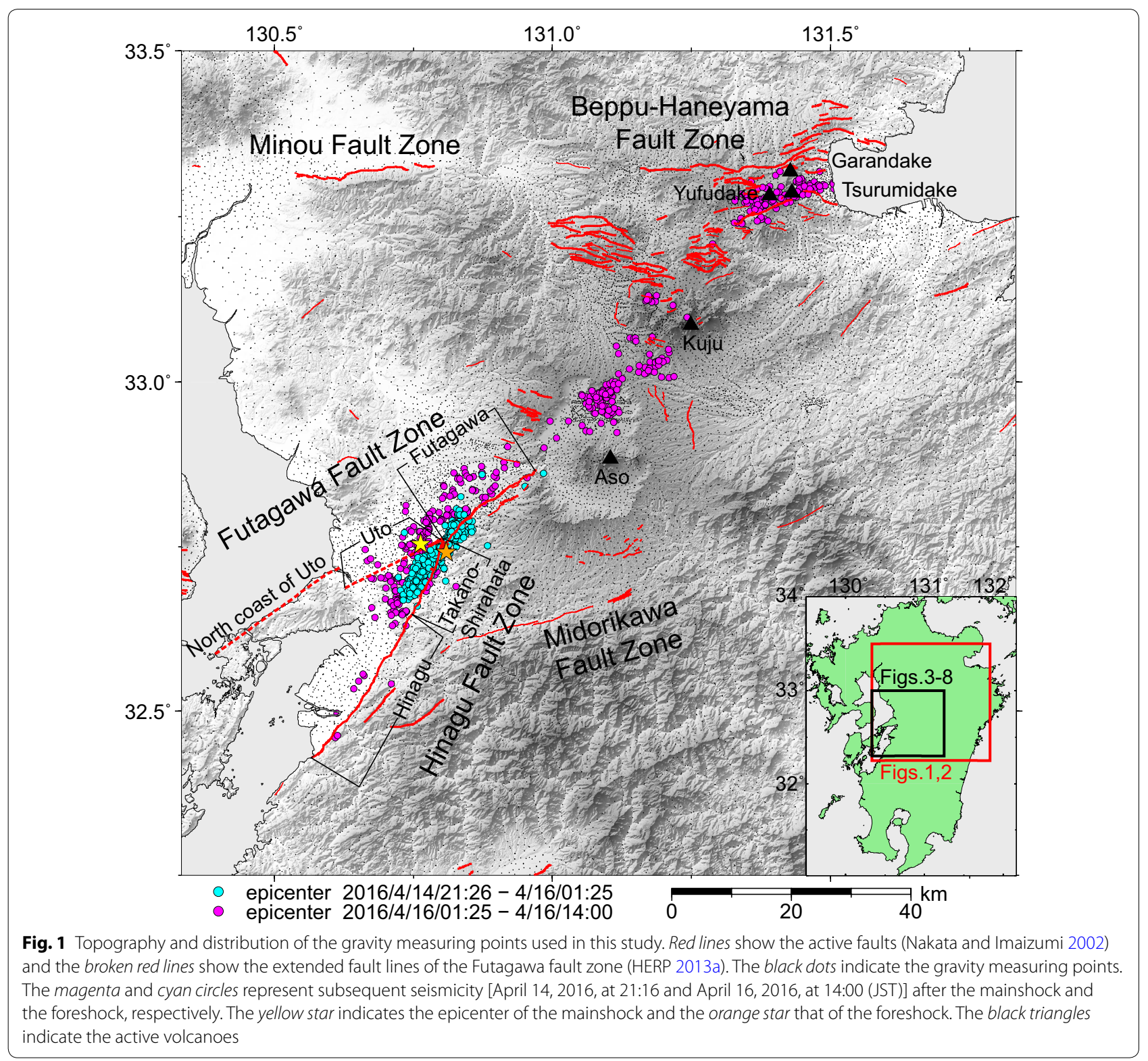




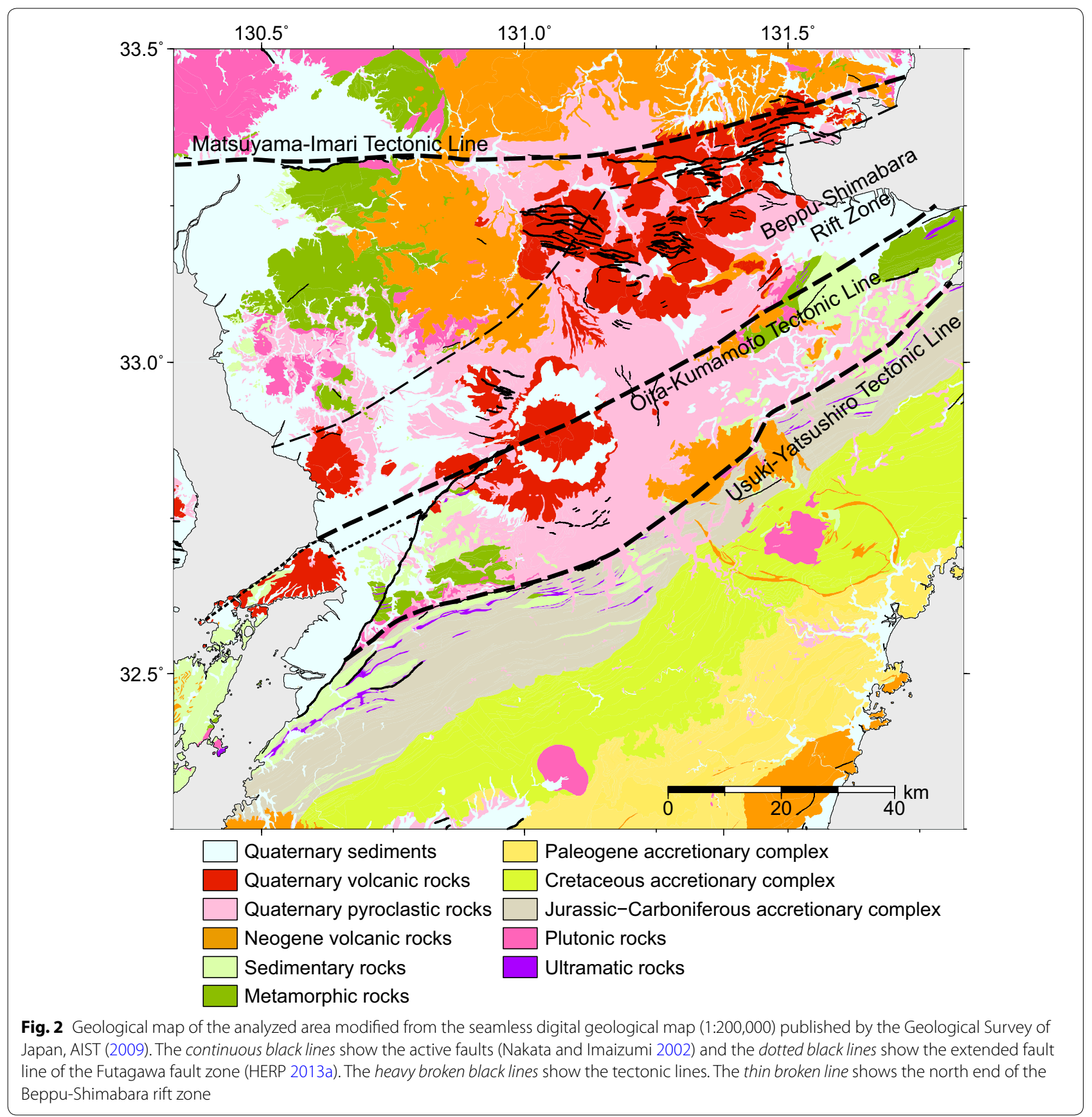

by a three-dimensional (3D) modeling with microgravity survey data.

In this study, we examine the subsurface structures in/ around the focal region through gravity anomalies. We calculate the first horizontal derivative (HD), the first vertical derivative (VD), the normalized total $\mathrm{HD}$, the dip angle of a two-dimensional structure and the dimensionality index, from the gravity gradient tensor. We discuss the continuity, segmentation and the faulting type of active fault zones, which caused the 2016 Kumamoto earthquake, through these derivatives and the structural parameters, together with the aftershock distribution.

\section{Data and methods}

\section{Gravity data and corrections}

We apply the gravity data published by the Gravity Research Group in Southwest Japan (2001), the Geographical Survey Institute (2006), Yamamoto et al. (2011), 
Honda et al. (2012) and the Geological Survey of Japan, AIST (2013), in this study. The distribution of the gravity measuring points is shown in Fig. 1 , and the total number of data points is 16,861 in the area shown. We apply terrain corrections with $10 \mathrm{~m}$ DEM (Sawada et al. 2015). The assumed density of the terrain corrections is $2670 \mathrm{~kg} / \mathrm{m}^{3}$ according to HERP (2013b). This density is suitable for the basement rocks around the Futagawa and the Hinagu fault zones, which are the Mesozoic and Paleozoic rocks. If we apply the assumed density of $2300 \mathrm{~kg} / \mathrm{m}^{3}$ for the terrain correction, then Bouguer anomalies tend to correlate with topography, indicating that the assumed density of $2300 \mathrm{~kg} / \mathrm{m}^{3}$ is not suitable. We also apply a low-pass filter with a cutoff wavelength of $10 \mathrm{~km}$ to emphasize a structure that corresponds to a scale of the segment of active fault zones, which is mainly $15-20 \mathrm{~km}$, and to reduce local singularities of derivative values mentioned in the next subsection. Finally, a linear trend is removed to obtain the Bouguer anomalies.

\section{Derivatives and structural parameters calculated from a gravity gradient tensor}

We use the first HD, the first VD and the normalized total horizontal derivative (TDX) (Cooper and Cowan 2006), to detect structural boundaries, and also the dip angle $(\beta)$ (Beiki 2013) and the dimensionality index $\left(D_{\mathrm{i}}\right)$ (Beiki and Pedersen 2010), as structural parameters to evaluate the subsurface fault structure (Kusumoto 2015). These derivatives and structural parameters are calculated from a gravity gradient tensor.

We follow a technique using a Fourier transform to calculate a gravity gradient tensor $(\Gamma)$ from a Bouguer anomaly proposed by Mickus and Hinojosa (2001), as indicated below. The gravity gradient tensor is defined with the gravity vector $\mathbf{g}=\left(g_{x}, g_{y}, g_{z}\right)$ as

$$
\Gamma=\left[\begin{array}{lll}
\frac{\partial g_{x}}{\partial x} & \frac{\partial g_{x}}{\partial y} & \frac{\partial g_{x}}{\partial z} \\
\frac{\partial g_{y}}{\partial x} & \frac{\partial g_{y}}{\partial y} & \frac{\partial g_{y}}{\partial z} \\
\frac{\partial g_{z}}{\partial x} & \frac{\partial g_{z}}{\partial y} & \frac{\partial g_{z}}{\partial z}
\end{array}\right]=\left[\begin{array}{lll}
g_{x x} & g_{x y} & g_{x z} \\
g_{y x} & g_{y y} & g_{y z} \\
g_{z x} & g_{z y} & g_{z z}
\end{array}\right] .
$$

where $g_{z}$ is measured on a horizontal surface in the $(x$, $y)$-plane.

The gravity potential $\phi$ satisfies Laplace's equation, $\nabla^{2} \phi=0$. The Fourier transform of $\phi(\Phi(\mathbf{k}))$ thus satisfies $\left(k_{x}^{2}+k_{y}^{2}+k_{z}^{2}\right) \Phi(\mathbf{k})=0$, where $\mathbf{k}=\left(k_{x}, k_{y}, k_{z}\right)$ is the wavenumber vector and $k_{x}, k_{y}$ and $k_{z}$ are the wavenumbers in the $x$-, $y$ - and $z$-directions, respectively. Then, the wave number $k_{z}$ can be expressed in terms of $k_{x}$ and $k_{y}$ as $-i k_{z}=|\mathbf{k}|$, where $|\mathbf{k}|=\left(k_{x}^{2}+k_{y}^{2}\right)^{1 / 2}$ (e.g., Blakely 1996). Finally, together with $\nabla \times \mathbf{g}=0$, the gravity gradient tensor is expressed as

$$
\Gamma=\mathcal{F}^{-1}\left\{[K(\mathbf{k})] G_{z}(\mathbf{k})\right\},
$$

where $\mathcal{F}^{-1}$ is the inverse Fourier transform operation, $G_{z}$ is the two-dimensional Fourier transform of $g_{z}$ and

$$
[K(\mathbf{k})]=\left[\begin{array}{ccc}
\frac{-k_{x}^{2}}{|\mathbf{k}|} & \frac{-k_{x} k_{y}}{|\mathbf{k}|} & -i k_{x} \\
\frac{-k_{x} k_{y}}{|k|} & \frac{-k_{y}^{2}}{|\mathbf{k}|} & -i k_{y} \\
-i k_{x} & -i k_{y} & |\mathbf{k}|
\end{array}\right] .
$$

From the gravity gradient tensor, HD, VD and TDX (Cooper and Cowan 2006) are defined as

$$
\begin{aligned}
\mathrm{HD} & =\sqrt{g_{z x}^{2}+g_{z y}^{2}}, \\
\mathrm{VD} & =g_{z z}, \\
\mathrm{TDX} & =\tan ^{-1}\left(\frac{\mathrm{HD}}{|\mathrm{VD}|}\right) \\
& =\tan ^{-1}\left(\frac{\sqrt{g_{z x}^{2}+g_{z y}^{2}}}{\left|g_{z z}\right|}\right) .
\end{aligned}
$$

These derivatives work as a high-pass filter, which detect relatively shallow and detailed structures. HD evaluates horizontally steep gravity gradients. Therefore, HD is often used to detect faults and structural boundaries (Kudo and Kono 1999; Yamamoto 2003; Honda et al. 2005; Kusumoto 2015, 2016). The maximal value of HD is more sensitive to shallower structure boundaries, so deep structures are occasionally underestimated (SEGJ 1998). VD does not emphasize the short-wavelength structures too much. Thus, VD is used to detect density boundaries such as geological boundaries the size and distribution depth of which are in a middle range (Sawada et al. 2012; Kusumoto 2016). Structural boundaries are recognized as zero isolines of VD, which indicate the inflection points of gravity anomalies (SEGJ 1998). TDX can detect both short- and long-wavelength components and is useful for detecting geological boundaries, as well as VD (Kusumoto 2016).

For two-dimensional (2D) structures, the minimum and maximum eigenvectors of the gravity tensor represent the strike and dip angles, respectively (Beiki 2013). $\beta$ is defined by the components of the maximum eigenvector, $v_{1 x}, v_{1 y}, v_{1 z}$, as

$$
\beta=\tan ^{-1}\left(\frac{v_{1 z}}{\sqrt{v_{1 x}^{2}+v_{1 y}^{2}}}\right) .
$$

The distribution of $\beta$ along a fault zone can be useful for evaluating a faulting type if the subsurface structure is assumed to be 2D-like (Kusumoto 2015). Kusumoto (2015) showed that a decrease in dip angle with depth was 
observed for a normal fault and an increase with depth was observed for a reverse fault, from a numerical simulation.

$D_{\mathrm{i}}$ evaluates the dimension of the subsurface structure, 2D or 3D (Beiki and Pedersen 2010). $D_{\mathrm{i}}$ is close to 0 or 1 , respectively, depending on whether the dimension of the structure is $2 \mathrm{D}$ or $3 \mathrm{D}$. $D_{\mathrm{i}}$ is defined by using the eigenvalues of a gravity gradient tensor (Pedersen and Rasmussen 1990), $\lambda_{1}, \lambda_{2}, \lambda_{3}$, as

$$
D_{\mathrm{i}}=\frac{-27 I_{2}^{2}}{4 I_{1}^{3}},
$$

where $I_{1}=\lambda_{1} \lambda_{2}+\lambda_{2} \lambda_{3}+\lambda_{1} \lambda_{3}$, and $I_{2}=\lambda_{1} \lambda_{2} \lambda_{3}$.

\section{Results}

\section{Subsurface fault structures related to the Futagawa fault} zone

Figure 3 shows a low-pass filtered Bouguer anomaly with a cutoff wavelength of $10 \mathrm{~km}$. Around the Aso volcano zone shows low Bouguer anomalies, lower than $-20 \mathrm{mGal}$, while the south of the Oita-Kumamoto tectonic line shows high Bouguer anomalies, higher than $0 \mathrm{mGal}$. These distributions are related closely to the geology in this area. The Aso volcano is filled with relatively light Quaternary volcanic and pyroclastic rocks (Fig. 2). On the other hand, heavier Mesozoic metamorphic rocks and Cretaceous sedimentary rocks are accumulated from the Oita-Kumamoto tectonic line to the Usuki-Yatsushiro tectonic line (Fig. 2).

A structural boundary, where the density boundary is clear, is generally detected as a higher value of $\mathrm{HD}$, a zero isoline of VD and/or a large, around $90^{\circ}$, TDX. The obtained HD (Fig. 4), VD (Fig. 5) and TDX (Fig. 6) clearly illustrate the continuous subsurface structural boundary from the Uto Peninsula to the west end of the Aso volcano along the Futagawa fault zone. In Fig. 1, we show the distribution of earthquakes between April 14, 2016, at 21:16 and April 16, 2016, at 14:00 JST, which includes the aftershocks of the foreshock and the mainshock. The aftershocks are distributed along this structural boundary from the confluence of the Futagawa and the Hinagu fault zones to the east end of the Aso volcano, indicating the existence of a fault structure.

Figure 7 shows the distribution of the dip angle $\beta$. Kusumoto (2015) demonstrated that the dip angle increases with depth along a reverse fault, while it decreases with depth along a normal fault based on a numerical simulation with a 3D fault model. $\beta$ indicates the dip angle only when the assumed structure is $2 \mathrm{D}$-like, that is, $D_{\mathrm{i}} \leq 0.5$ (Beiki 2013) (Fig. 8). Focusing on $\beta$ around the fault zone, the distribution of $\beta$ across the Futagawa segment decreases from the south to the north. The Futagawa fault is dipping to the northwest (GSI 2016a). The dip

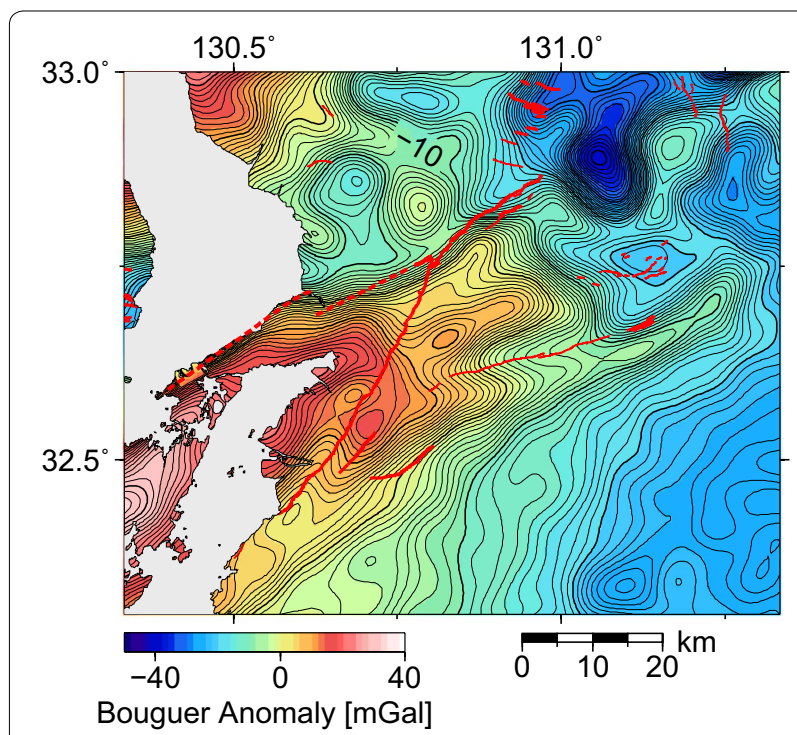

Fig. 3 Bouguer anomaly distribution of the analyzed area. A low-pass filter with a cutoff wavelength of $10 \mathrm{~km}$ is applied. The assumed density of the terrain corrections is $2670 \mathrm{~kg} / \mathrm{m}^{3}$. The continuous red lines show active faults (Nakata and Imaizumi 2002) and the broken red lines show the extended fault line of the Futagawa fault zone (HERP 2013a)

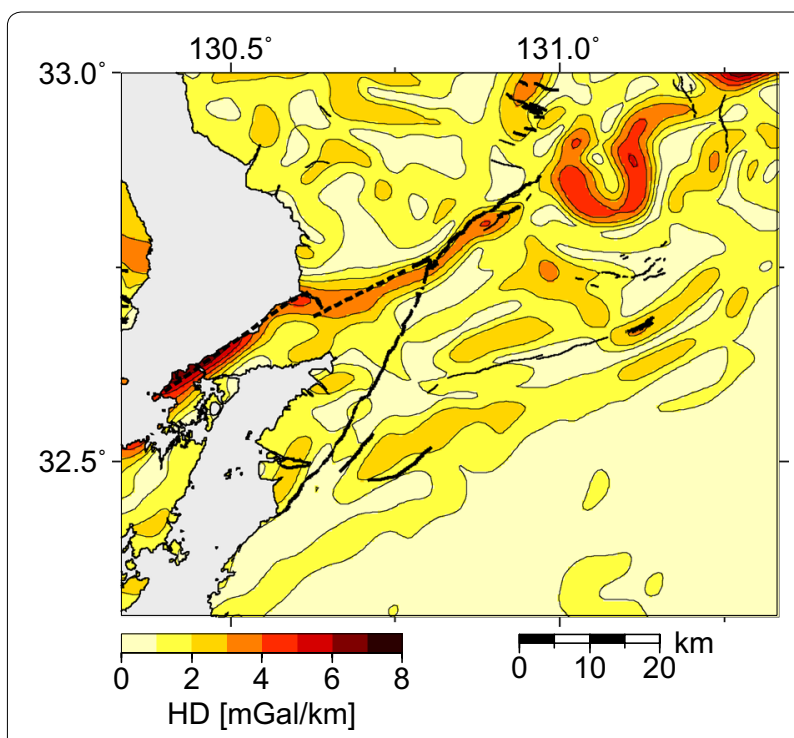

Fig. 4 First horizontal derivative (HD) distribution of the Bouguer anomaly shown in Fig. 3. A structural boundary is recognized as higher values. The continuous black lines show active faults (Nakata and Imaizumi 2002) and the broken black lines show the extended fault line of the Futagawa fault zone (HERP 2013a)

angle distribution across the Futagawa segment, therefore, implies a normal fault, corresponding to the faulting of the focal mechanism of the 2016 Kumamoto earthquake (HERP 2016). 


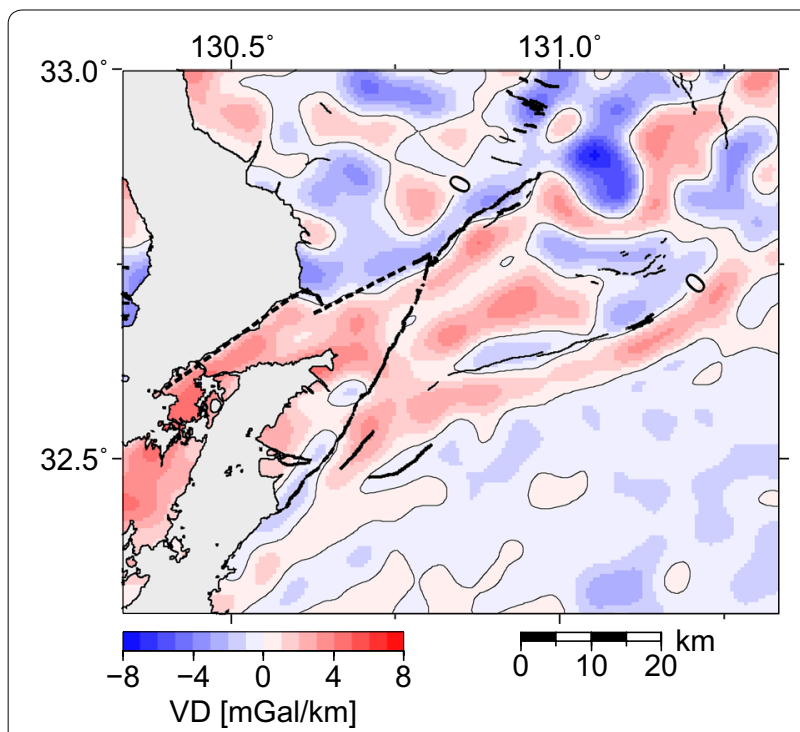

Fig. 5 First vertical derivative (VD) distribution of the Bouguer anomaly shown in Fig. 3. A structural boundary is recognized as a zero isoline. The continuous black lines show active faults (Nakata and Imaizumi 2002) and the broken black lines show the extended fault line of the Futagawa fault zone (HERP 2013a)

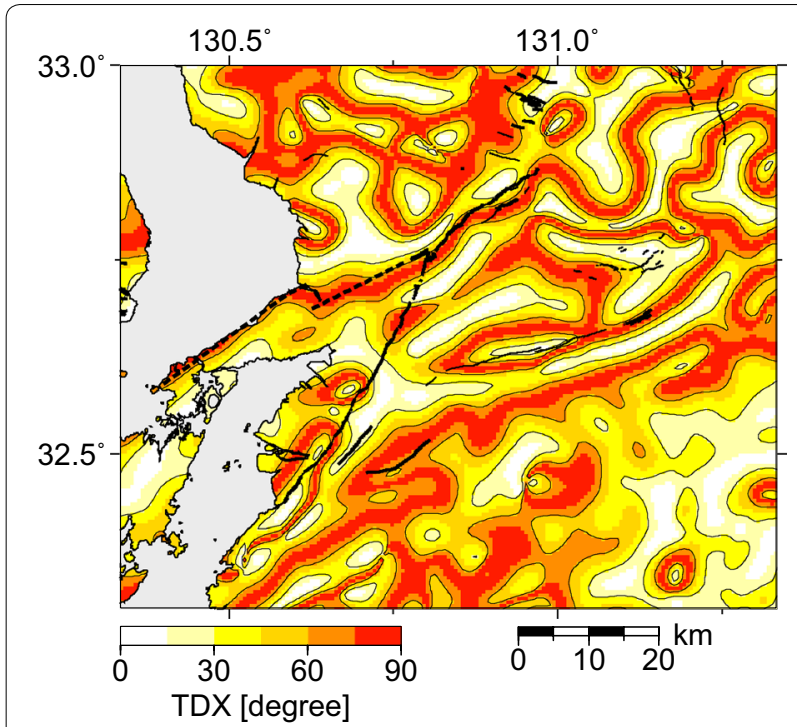

Fig. 6 Normalized total horizontal derivative (TDX) distribution of the Bouguer anomaly shown in Fig. 3. A structural boundary is recognized as large degree isoline. The continuous black lines show active faults (Nakata and Imaizumi 2002) and the broken black lines show the extended fault line of the Futagawa fault zone (HERP 2013a)

\section{Subsurface fault structures related to the Hinagu fault zone}

Bouguer anomalies are high around the Hinagu fault zone. It is interesting that the contour lines around the southern part of the Hinagu segment and the
Midorikawa fault zone show an S-shaped distribution across the fault (Fig. 3). According to Hagiwara (1987), a lateral displacement of a geological structure can be recognized from Bouguer anomalies as changes in contour direction and interval, discontinuous contour and S- or U-shaped features across a fault. For example, S-shaped contours of Bouguer anomalies are observed over a left lateral displacement of the Naguri fault (Hagiwara et al. 1997). Thus, we consider that the S-shaped distributions observed for the Hinagu segment and the Midorikawa fault zone indicate a right lateral faulting (Fig. 3). This is consistent with the geological and geomorphological estimation of the faulting (HERP 2013a, c).

The VD and TDX show the existence of a subsurface structural boundary, which is a fault structure, along the southern part of the Hinagu segment, but it is not so clear (Figs. 5, 6). Focusing on $\beta$ around the fault zone, the distribution of $\beta$ across the Hinagu segment, which decreases from the southwest to the northeast, implies a normal faulting (Fig. 7). No clear structural boundaries are observed along the Takano-Shirahata segment (Figs. 4, 5, 6), although most of the aftershocks occurred around this segment (Fig. 1). Around the segment boundary between the Takano-Shirahata and the Hinagu segments, the large value of TDX is not continuous along the fault zone (Fig. 6) and $D_{\mathrm{i}}$ shows the existence of a 3D-like structure with a NW-SE trend (Fig. 8).

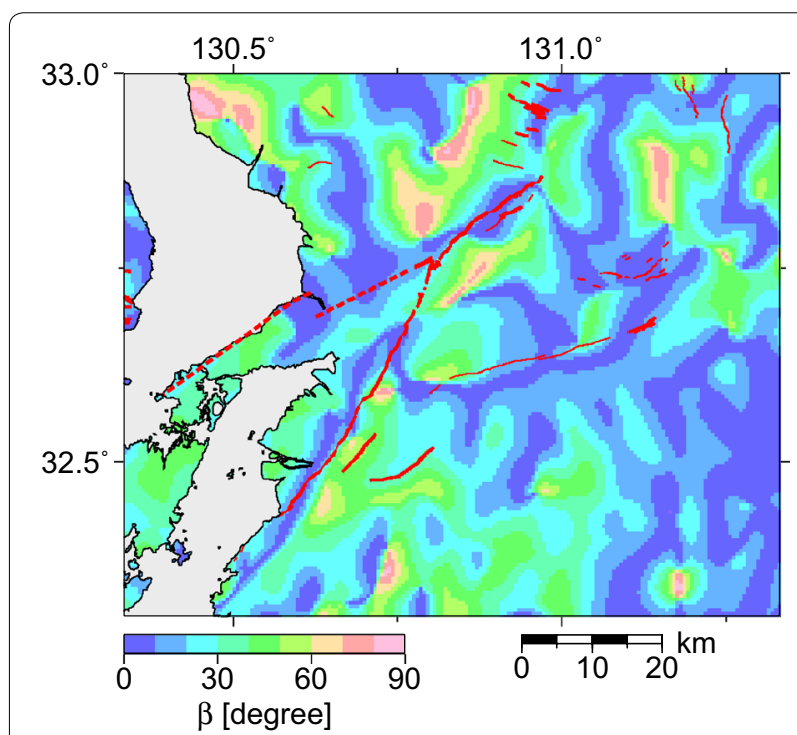

Fig. 7 Dip angle ( $\beta$ ) distribution. For a two-dimensional structure, a decrease and an increase with depth indicate a normal fault structure and a reverse fault structure, respectively. The continuous red lines show active faults (Nakata and Imaizumi 2002) and the broken red lines show the extended fault line of the Futagawa fault zone (HERP 2013a) 


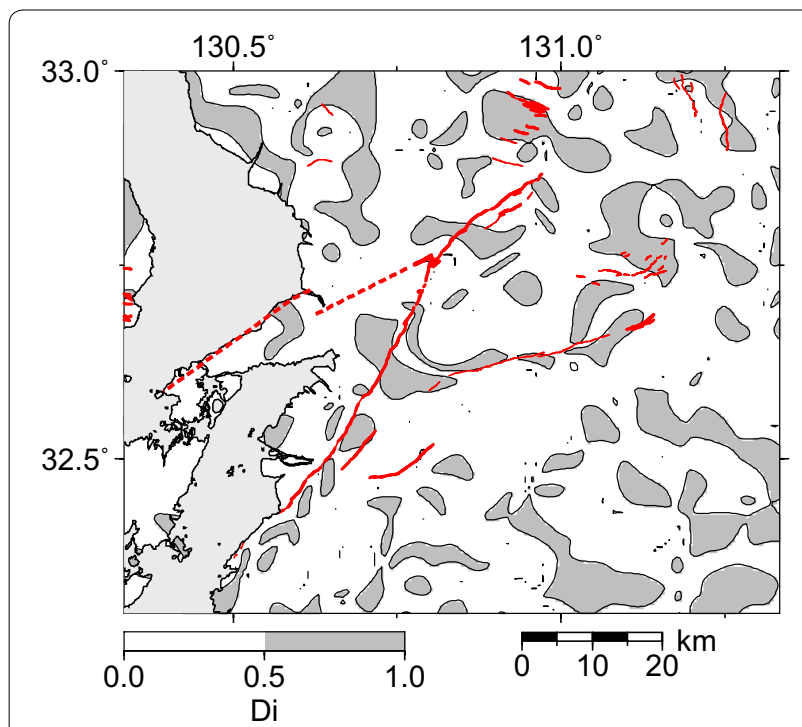

Fig. 8 Dimensionality index $\left(D_{\mathrm{i}}\right)$ distribution. $D_{\mathrm{i}}$ is close to 0 or 1 depending on whether the dimension of a structure is $2 \mathrm{D}$ or $3 \mathrm{D}$. The continuous red lines show active faults (Nakata and Imaizumi 2002) and the broken red lines show the extended fault line of the Futagawa fault zone (HERP 2013a)

\section{Discussion}

In the previous section, we have characterized the features of the subsurface fault structures of the Futagawa and the Hinagu fault zones. We focus here on the difference in features between these two fault zones and discuss the segmentation of the Hinagu fault zone based on the aftershock distribution and the size of the source fault estimated from a geodetic investigation.

We recognize the subsurface fault structures through HD, VD and TDX more clearly along the Futagawa fault zone than the Hinagu fault zone (Figs. 4, 5, 6), indicating that the cumulative vertical displacement of the Futagawa fault zone is larger than that of the Hinagu fault zone. This result is supported by GNSS data, which indicate that the subsidence velocity is remarkably large around the middle part of the Oita-Kumamoto tectonic line (HERP 2013b). Also, the vertical crustal deformation of the 2016 Kumamoto earthquake is larger in the western part of this tectonic line (GSI 2016c). However, from the derivatives, it is difficult to find a continuous subsurface structure along the Takano-Shirahata segment.

The average vertical slip rate of the Takano-Shirahata segment is $0.04-0.2 \mathrm{~mm} /$ year (NUPEC 1996), which is relatively small, while that of the Futagawa segment is 0.1-0.3 mm/year (Kumamoto Prefecture 1996a, b) and that of the Hinagu segment is $0.2-0.5 \mathrm{~mm}$ /year (HERP 2013a). In addition, surface traces of the fault around the Takano-Shirahata segment are intermittent and the direction of the displacement is irregular (HERP 2013a).
This supports the smaller average vertical slip rate of the segment. Therefore, the undetected subsurface structure infers that the cumulative vertical displacement of the Takano-Shirahata segment is not large enough to be detected by Bouguer anomalies.

Around the boundary between the Takano-Shirahata and the Hinagu segments, the discontinuity of a large value of TDX, and a zone of $D_{\mathrm{i}}$ larger than 0.5 are distributed across the fault zone with a NW-SE trend (Figs. 6, $8)$. This suggests that a 2D-like subsurface structure, such as a fault, is discontinuous at this boundary. Also, the active area of the aftershocks does not extend to the south beyond this structural boundary. Furthermore, the result of multiple aperture interferometry (GSI 2016b) suggests that the displacement is diminished around the segment boundary. The fault model of the foreshock estimated from the coseismic crustal deformation is restricted in the Takano-Shirahata segment (GSI 2016a). These observations imply that the source fault of the 2016 Kumamoto earthquake does not extend to the south beyond this boundary. Therefore, we conclude that this boundary detected by the TDX and $D_{\mathrm{i}}$ controls the spatial extent of the source fault.

The geological map indicates that this boundary corresponds to a boundary between metamorphic rocks and sedimentary rocks on the ground surface (Fig. 2). According to Honda et al. (2002), the source area at the 2002 Tottori-ken Seibu earthquake was also limited by the geological boundary between granite and Sangun metamorphic rocks. It is, therefore, important for a more accurate characterization of the subsurface continuity and segmentation of an active fault to interpret gravity anomalies, together with geological and geomorphological information.

In this study, we show that gravity analysis enables the determination of the features, continuity, segmentation, faulting type and dipping direction of an active fault zone which occur as a result of large earthquakes. The gravity data used in this study were obtained prior to the Kumamoto earthquake. We emphasize that an effective use of gravity anomalies can enhance the understanding of active faults.

\section{Conclusions}

We have used derivatives and structural parameters derived from a gravity gradient tensor calculated from Bouguer anomalies to investigate the subsurface structure of the active fault zones related to the 2016 Kumamoto earthquake. The continuous subsurface fault structure along the Futagawa fault zone is clearly detected with HD, VD and TDX. The distribution of $\beta$ around the Futagawa segment implies a normal faulting. In the Hinagu fault zone, structural boundaries are not 
detected along the Takano-Shirahata segment, reflecting a smaller average vertical slip rate and unclear surface traces. In the Hinagu segment, Bouguer anomalies show an S-shaped distribution, which indicates a right lateral faulting, and subsurface fault structures are detected with VD and TDX. Furthermore, the distribution of $\beta$ implies a normal faulting. Around the segment boundary between the Hinagu segment and the Takano-Shirahata segment, we detect the structural boundary with TDX and $D_{\mathrm{i}}$, which corresponds to a geological boundary. The aftershock distribution and geodetic observations suggest that a spatial extent of the source fault is controlled by this boundary. Gravity analysis is a useful method to evaluate the continuity, segmentation and faulting type of active fault zones.

\section{Abbreviations}

HD: first horizontal derivative; VD: first vertical derivative; TDX: normalized total horizontal derivative; $D_{i}$ : dimensionality index; $\beta$ : dip angle; $2 \mathrm{D}$ : two-dimensional; 3D: three-dimensional.

\section{Authors' contributions}

NM conducted the analyses. AS maintained the gravity data. NM and $\mathrm{YH}$ participated in the design of this study and drafted the manuscript. All authors read and approved the final manuscript.

\section{Author details}

${ }^{1}$ Graduate School of Natural Science and Technology, Kanazawa University, Kakuma, Kanazawa 920-1192, Japan. ${ }^{2}$ School of Natural System, College of Science and Engineering, Kanazawa University, Kakuma, Kanazawa 920-1192, Japan.

\section{Acknowledgements}

This study was supported by the Japan Society for the Promotion of Science (JSPS) KAKENHI Grant No. 26400450. The gravity data published by the Gravity Research Group in Southwest Japan (2001), the Geographical Survey Institute (2006), Yamamoto et al. (2011), Honda et al. (2012) and the Geological Survey of Japan, AIST (2013), have been used in this study. All the figures are produced using the Generic Mapping Tools software (Wessel and Smith 1998).

\section{Competing interests}

The authors declare that they have no competing interests.

Received: 29 July 2016 Accepted: 6 October 2016

Published online: 21 October 2016

\section{References}

Beiki M (2013) TSVD analysis of Euler deconvolution to improve estimating magnetic source parameters: an example from the Åsele area, Sweden. J Appl Geophys 90:82-91

Beiki M, Pedersen LB (2010) Eigenvector analysis of gravity gradient tensor to locate geologic bodies. Geophysics 75(6):137-149

Blakely RJ (1996) Potential theory in gravity and magnetic applications. Cambridge University Press, Cambridge

Cooper GRJ, Cowan DR (2006) Enhancing potential field data using filters based on the local phase. Comput Geosci 32:1585-1591

Fedi M, Ferranti L, Florio G, Giori I, Italiano F (2005) Understanding the structural setting in the southern Apennines (Italy): insight from gravity gradient tensor. Tectonophysics 397:21-36

Geographical Survey Institute (2006) Search of gravity data (in Japanese). http://vldb.gsi.go.jp/sokuchi/gravity/grv_search/gravity.pl. Accessed 26 Dec 2015
Geological Survey of Japan, AIST (ed) (2009) Seamless digital geological map of Japan at a scale of 1:200,000, DVD edn. Geological Survey of Japan, AIST, Tsukuba

Geological Survey of Japan, AIST (ed) (2013) Gravity database of Japan DVD edition, digital geoscience map P-2. Geological Survey of Japan, AIST, Tsukuba

Geospatial Information Authority of Japan (2016a) Coseismic fault model of the 2016 Kumamoto earthquake (in Japanese). http://www.gsi.go.jp/ common/000140781.pdf. Accessed 20 May 2016

Geospatial Information Authority of Japan (2016b) Crustal deformation around the faults revealed by MAI analysis of the 2016 Kumamoto earthquake. http://www.gsi.go.jp/cais/topic160428-index-e.html. Accessed 30 Apr 2016

Geospatial Information Authority of Japan (2016c) Vertical crustal deformation of the 2016 Kumamoto earthquake (in Japanese). http://www.gsi.go.jp/ common/000139641.jpg. Accessed 20 May 2016

Gravity Research Group in Southwest Japan (2001) Bulletin of the Nagoya University Museum, special report no. 9. Nagoya University Museum, Nagoya

Hagiwara Y (1987) Gravity anomaly over active faults. Act Fault Res 4:9-17 (in Japanese)

Hagiwara Y, Itota C, Ohki Y, Kitamura Y (1997) Left-lateral displacement of the Naguri fault as inferred from gravity anomaly. Act Fault Res 16:7-12 (in Japanese with English abstract)

Headquarters for Earthquake Research Promotion (2013a) Evaluation of the Futagawa and the Hinagu fault zones (partly revised) (in Japanese). http://jishin.go.jp/main/chousa/katsudansou_pdf/93_futagawa_ hinagu_2.pdf. Accessed 20 Apr 2016

Headquarters for Earthquake Research Promotion (2013b) Long-term evaluation of active faults in Kyushu region, 1st edn (in Japanese). http://jishin. go.jp/main/chousa/13feb_chi_kyushu/k_honbun.pdf. Accessed 20 Apr 2016

Headquarters for Earthquake Research Promotion (2013c) Evaluation of the Midorikawa fault zone (in Japanese). http://www.jishin.go.jp/main/ chousa/13feb_chi_kyushu/k_12.pdf. Accessed 20 Apr 2016

Headquarters for Earthquake Research Promotion (2016) Evaluation of the 2016 Kumamoto earthquake (in Japanese). http://www.static.jishin. go.jp/resource/monthly/2016/2016_kumamoto_3.pdf. Accessed 20 May 2016

Honda R, Hiramatsu Y, Kono Y (2002) Gravity anomaly over the focal region of the 2000 Tottori-ken Seibu earthquake and the features of the earthquake source fault. J Seismol Soc Jpn 55(1):83-88 (in Japanese)

Honda R, Hiramatsu Y, Furumoto M, Kono Y (2005) A relationship between horizontal gravity gradient and zones with large strain rates. J Seismol Soc Jpn 58(3):371-373 (in Japanese)

Honda R, Hiramatsu Y, Kono Y, Katagawa H (2008) Gravity anomalies and the geologic block structures in and around the aftershock area of the 2007 Noto Hanto Earthquake. Earth Planets Space 60(2):111-115

Honda R, Sawada A, Furuse N, Kudo T, Tanaka T, Hiramatsu Y (2012) Release of gravity database of the Kanazawa University. J Geod Soc Jpn 58(4):153160 (in Japanese with English abstract)

Japan Meteorological Agency (2016a) Press release report about the earthquake in Kumamoto region on April 142016 at 21:26 JST (in Japanese). http://www.jma.go.jp/jma/press/1604/14a/kaisetsu201604142330.pdf. Accessed 18 Apr 2016

Japan Meteorological Agency (2016b) Press release report about the 2016 Kumamoto earthquake, part 7 (in Japanese). http://www.jma.go.jp/jma/ press/1604/16a/kaisetsu201604160330.pdf Accessed 18 Apr 2016

Kudo K, Kono Y (1999) Relationship between distributions of shallow earthquakes and gradients of gravity anomaly field in southwest Japan. J Seismol Soc Jpn 52(3):341-350 (in Japanese with English abstract)

Kumamoto Prefecture (1996a) Research report of the Futagawa fault zone (digest version). Kumamoto Prefecture, Kumamoto (in Japanese)

Kumamoto Prefecture (1996b) Progress report of the Futagawa fault and the Tatsudayama fault. Kumamoto Prefecture, Kumamoto (in Japanese)

Kusumoto S (2015) Estimation of dip angle of fault or structural boundary by eigenvectors of gravity gradient tensors. Butsuri-Tansa 68(4):277-287 (in Japanese)

Kusumoto S (2016) Semi-automatic interpretation methods for extracting structural boundaries using gravity gradient tensors. Butsuri-Tansa 69(1):53-63 (in Japanese) 
Matsumoto Y (1979) Some problems on volcanic activities and depression structures in Kyushu, Japan. Mem Geol Soc Jpn 16:127-139 (in Japanese with English abstract)

Mickus KL, Hinojosa JH (2001) The complete gravity gradient tensor derived from the vertical component of gravity: a Fourier transform technique. $J$ Appl Geophys 46:159-174

Nakata T, Imaizumi T (eds) (2002) Digital active fault map of Japan (DVD-ROM). University of Tokyo Press, Tokyo (in Japanese)

National Institute of Advanced Industrial Science and Technology, AIST, Faculty of Science, Chiba university, School of Marin Science and Technology, Tokai University, and Geo-Research Institute (2010) Progress report of active faults research in coastal zones: the northern (sea area) and the eastern (southern) parts of the Unzen fault group (in Japanese). HERP, Tokyo. http://jishin.go.jp/main/chousakenkyuu/engankaiiki/h21/h21_ unzen.pdf. Accessed 10 May 2016

Nishijima J, Fujimitsu Y (2015) Precise gravity survey around Minou fault system, Fukuoka prefecture, Japan-relationship between fault strictures and hot springs. J Geotherm Res Soc Jpn 37(2):41-49 (in Japanese with English abstract)

Nuclear Power Engineering Corporation (1996) Report of confirmation research on nuclear power plant site (1). Nuclear Power Engineering Corporation, Tokyo (in Japanese)

Pedersen LB, Rasmussen TM (1990) The gradient tensor of potential field anomalies: some implications on data collection and data processing of maps. Geophysics 55(12):1558-1566

Sawada A, Hiramatsu Y, Mizubayashi T, Hamada M, Honda R (2012) Geological block structures in the northern Noto Peninsula, through gravity anomalies. J Seismol Soc Jpn 64(4):235-239 (in Japanese)
Sawada A, Honda R, Hiramatsu Y (2015) Improvement of the gravity database of Kanazawa University. In: The 133rd Society of Exploration Geophysicists of Japan conference, 24 September, p 3

Society of Exploration Geophysicists of Japan (1998) Handbook for exploration geophysicists. Society of Exploration Geophysicists of Japan, Tokyo (in Japanese)

Sugiyama Y, Okamura Y, Takeda N, Maruyama K (2010) Sonic survey of the Unzen fault group in Shimabara and Tachibana Bays, central Kyushu. In: Annual report on active fault and paleoearthquake researches, vol 10, pp 149-194. Geological Survey of Japan, AIST, Tsukuba (in Japanese with English abstract)

Tada T (1984) Spreading of the Okinawa trough and its relation to the crustal deformation in Kyushu. J Seismol Soc Jpn 37(3):407-415 (in Japanese with English abstract)

Tada T (1985) Spreading of the Okinawa trough and its relation to the crustal deformation in Kyushu (2). J Seismol Soc Jpn 38(1):1-12 (in Japanese with English abstract)

Takayama H, Yoshida A (2007) Crustal deformation in Kyushu derived from GEONET data. J Geophys Res. doi:10.1029/2006JB004690

Wessel P, Smith WHF (1998) New, improved version of the generic mapping tools released. EOS Trans Am Geophys Union 79(47):579

Yamamoto A (2003) Gravity anomaly atlas of the Ishikari plain and its vicinity Hokkaido, Japan. Geophys Bull Hokkaido Univ 66:33-62 (in Japanese with English abstract)

Yamamoto A, Shichi R, Kudo T (2011) Gravity database of Japan (CD-ROM). Special publication no. 1. The Earth Watch Safety Net Research Center, Chubu University, Nagoya

\section{Submit your manuscript to a SpringerOpen ${ }^{\circ}$ journal and benefit from:}

- Convenient online submission

- Rigorous peer review

- Immediate publication on acceptance

- Open access: articles freely available online

- High visibility within the field

- Retaining the copyright to your article 